\title{
Antioxidant status of barley seedlings under conditions of excess manganese
}

\author{
Olga Simonova ${ }^{1, *}$,Evgenija Tovstik $^{2}$, and Maksim Simonov ${ }^{2}$ \\ ${ }^{1}$ Federal Agricultural Research Center of the North-East named N.V. Rudnitsky, 610007 Kirov, \\ Russian Federation \\ ${ }^{2}$ Vyatka State University, 610000 Kirov, Russian Federation
}

\begin{abstract}
The system of protection against the effects of heavy metals (TM) can differ not only in different species of plants, but also in different varieties. Manganese (Mn), as a biogenic element, is necessary for normal plant growth and development. However, in the case of concentrations exceeding the optimal level, it negatively affects both linear plant growth and physiological processes. The paper presents data on the assessment of the effect of excess manganese (II) ions (30,60 and $90 \mathrm{mg} / 1$ of active substance) on barley seedlings of different varieties. Resistance of plants to ionic toxicity of manganese (II) was judged by the value of antioxidant activity (AOA) of superoxide dismutase (SOD), the content of lowmolecular antioxidants (chlorophyll a and $\mathrm{b}$, carotenoids and anthocyanins) in barley leaves. For most of the varieties studied, an increase in AOA of SOD, the content of anthocyanins indicating the activation of plant protective mechanisms, was noted. The amount of green pigments, as well as carotenoids, on the contrary, decreased, compared with the control, which indicated a violation of the processes of photosynthesis in them.
\end{abstract}

\section{Introduction}

Among heavy metals (HM), manganese is one of the most common chemical elements in the lithosphere. Its clark in the upper part of the continental crust is $770 \mathrm{mg} / \mathrm{kg}$, the average content in farmland soils varies from 45.4 to $3336.0 \mathrm{mg} / \mathrm{kg}[1,2]$. Regulated by HS 2.1.7.2041-06, the MPC of manganese in the soil, taking into account its clark, is 1500 $\mathrm{mg} / \mathrm{kg}$.

Despite the fact that manganese is needed by plants in small quantities, its importance for plant growth and development is large and no less significant than other nutrients [3]. Excess manganese in soils, as well as its deficiency, is a serious problem of crop yield reduction [4]. This is especially true for acidic soils, which include sod-podzolic soils of the Kirov region. In these soils, the negative effect of manganese on plant growth and development is increasing, but the degree of this effect on the physiological processes that take place in them is not sufficiently studied.

In general, the tolerance of plants to excess manganese is regulated by many factors, including the level of photosynthetic pigments in plant tissues $[5,6]$. Other physiological

\footnotetext{
${ }^{*}$ Corresponding author: simolga07@gmail.com
} 
and biochemical parameters of plants, in particular, antioxidant defense mechanisms, which are manifested as a result of an increase in reactive oxygen species under the influence of negative factors, can also act as markers of stress resistance [7]. In turn, the antioxidant properties of plants depend on the content of both high-molecular (SOD, etc.) and lowmolecular (green pigments, carotenoids, anthocyanins, etc.) antioxidants.

To date, it has been established that the resistance of plants to negative factors is largely determined by both their species and variety and depends on the content of antioxidants in them [8]. For example, under the influence of heavy metals, inhibition of pigment biosynthesis is recorded [9]. At the same time, a decrease in the content of carotenoids is less pronounced in more resistant varieties than in less resistant ones [10]. In some studies, it is noted that the content of carotenoids in leaves in the presence of heavy metals remains unchanged [11]. Therefore, the identification of varieties that are most resistant to the stress factors of the region is relevant.

The purpose of the work is to identify barley varieties resistant to high doses of manganese. The stress resistance parameters were: SOD activity and the content of lowmolecular antioxidants in plant leaves: green pigments (chlorophyll a and b), carotenoids and anthocyanins in plant leaves.

\section{Materials and methods}

The objects of the study were barley plants of varieties: Belgorodskij 100; 346-09; Forward; Farmer; 29-11; Bionik from the working collection of the laboratory of selection and primary seed production of barley of the FARC North-East.

The test was carried out in a roll culture on a nutrient solution of Knop: $\left(\mathrm{Ca}\left(\mathrm{NO}_{3}\right)_{2}-1\right.$; $\mathrm{K}_{3} \mathrm{PO}_{4}-0.25 ; \mathrm{MgSO}_{4} \times 7 \mathrm{H}_{2} \mathrm{O}-0.25 ; \mathrm{KCl}-0.125 \mathrm{~g}$ per 1 liter of water). Manganese (II) ions were added to the solution as $\mathrm{MnSO}_{4} \times \mathrm{H}_{2} \mathrm{O}$ at concentrations of 30,60 and $90 \mathrm{mg} / \mathrm{l}$, based on the active ingredient (The choice of manganese (II) ion concentrations was due to the fact that the maximum permissible concentrations (MPC) of manganese mobile compounds (recovered by acetate-ammonium buffer with $\mathrm{pH}=4.8$ ) for sod-podzolic soils with $\mathrm{pH}=4.0$ in accordance with HS 2.1.7.2041-06 is $60 \mathrm{mg} / \mathrm{kg}$. The manganese doses tested were 0.5 ; 1 and 1.5 MPC. The control was a Knop solution without the addition of manganese (II) ions. Barley seeds were placed in each roll in an amount of 33 pieces. The test was carried out in three times repetition. Barley cultivation of selected genotypes was carried out under natural conditions (temperatures $20^{\circ} \mathrm{C}$, photo period: light/darkness 16/8) for 14 days.

Superoxide dismutase activity was determined in barley leaves; chlorophyll content: a, b and carotenoids; anthocyanin content.

To determine the activity of SOD (AOA), a leaf suspension $(0.2-1.0$ g crude mass) was triturated with $10 \mathrm{ml}$ bicarbonate buffer $(\mathrm{pH}=10.30-10.65)$. The resulting solution was filtered through a paper filter. The calculation was carried out according to formula 1:

$$
\mathrm{AOA}=\frac{\left(\mathrm{OD}_{1}-\mathrm{OD}_{2}\right) \times 100 \%}{\mathrm{OD}_{1}},
$$

$\mathrm{OD}_{1}$ - optical density of $3 \mathrm{ml}$ bicarbonate buffer with $0.1 \mathrm{ml}$ of $0.1 \%$ adrenaline hydrochloride solution; $\mathrm{OD}_{2}$ - optical density of $2 \mathrm{ml}$ of buffer with addition of $1 \mathrm{ml}$ of filtrate and $0.1 \mathrm{ml}$ of $0.1 \%$ adrenaline hydrochloride solution.

Optical density was measured at $347 \mathrm{~nm}$ after 2 hours on a UVmini-1240 spectrophotometer (Shimadzu Corporation, Japan) [12].

The content of the main forms of photosynthetic pigments (chlorophylls a, b, and carotenoids) in plant leaves was determined by spectrophotometry at wavelengths of 661.6, 
$644.8 \mathrm{~nm}$ (chlorophylls), and $470 \mathrm{~nm}$ (carotenoids). The samples were extracted with $100 \%$ acetone. The pigment concentration was calculated using formulas 2-4 [13].

$$
\begin{aligned}
& C_{a}=11.24 \times \mathrm{D}_{661.6}-2.04 \times \mathrm{D}_{644.8} ; \\
& C_{b}=20.13 \times \mathrm{D}_{644.8}-4.19 \times \mathrm{D}_{661.6} ; \\
& C_{k}=\frac{1000 \times D_{470}-1.90 \times C_{a}-63.14 \times C_{b}}{214},
\end{aligned}
$$

$C_{a}$ - chlorophyll concentration a $(\mathrm{mg} / \mathrm{l}) ; C_{b}$ - chlorophyll b concentration $(\mathrm{mg} / \mathrm{l}) ; C_{k}-$ concentration of carotenoids $(\mathrm{mg} / \mathrm{l}) ; \mathrm{D}_{470} ; \mathrm{D}_{644.8} ; \mathrm{D}_{661.6}$ - optical density of the solution at $470 ; 644.8 ; 661.6 \mathrm{~nm}$, respectively.

Total content in the test sample according to formula 5 :

$$
X=\frac{C \times \mathrm{V} \times 0.001}{m}
$$

$X$ - pigment content in the test sample $(\mathrm{mg} / \mathrm{g})$;

$C$ - pigment concentration $(\mathrm{mg} / \mathrm{g})$;

$\mathrm{V}-$ the volume of the pigment extract $\left(\mathrm{cm}^{3}\right)$;

$m$ - the sample weight $(\mathrm{g})$;

0.001 - pigment concentration conversion factor.

Additionally, the mass ratio of the sum of chlorophylls to carotenoids $((\mathrm{a}+\mathrm{b})$ /carotenoids) was calculated.

To determine the anthocyanin content, a sample of fresh leaves weighing $0.2-1 \mathrm{~g}$ was taken, ground in a porcelain mortar, and $10 \mathrm{ml}$ of $1 \%$ hydrochloric acid solution was added [9]. The resulting solution was filtered. The total amount of anthocyanins in the sample was calculated using the formula using the specific absorption index of cyanidin-3,5-diglycoside in a $1 \%$ aqueous solution of hydrochloric acid (453 units).

The content of anthocyanins (X) was calculated using the formula 6:

$$
\mathrm{X}=\frac{\left(\mathrm{D}_{510}-1 / 3 \mathrm{D}_{657}\right) \times \mathrm{V} \times 100 \%}{E_{1 \mathrm{~cm}}^{1 \%} \times \mathrm{A}}
$$

$\mathrm{D}_{510} ; \mathrm{D}_{657}$ - the optical density of the solution at $510 ; 657 \mathrm{~nm}$, respectively; $\mathrm{V}$ - the volume of the extract (ml); E - the specific absorption index of cyanidin-3.5 diglycoside at a wavelength of $510 \mathrm{~nm}$ in a $1 \%$ aqueous solution of hydrochloric acid, equal to 453 (units); $\mathrm{A}-$ the mass of the raw material $(\mathrm{g})$.

Statistical data processing was performed using the MS Excel software package. The average values and their standard errors were calculated for the numerical characteristics of physiological parameters. The significance of the differences between the variants was determined with a confidence probability $\mathrm{P} \geq 0.95$. The AOA of SOD in the experimental variants was estimated in \% relative to the control (growing medium without the addition of $\mathrm{Mn})$.

\section{Results and discussions}

The level of SOD activity in the leaves differed in different varieties of barley (Fig. 1). 


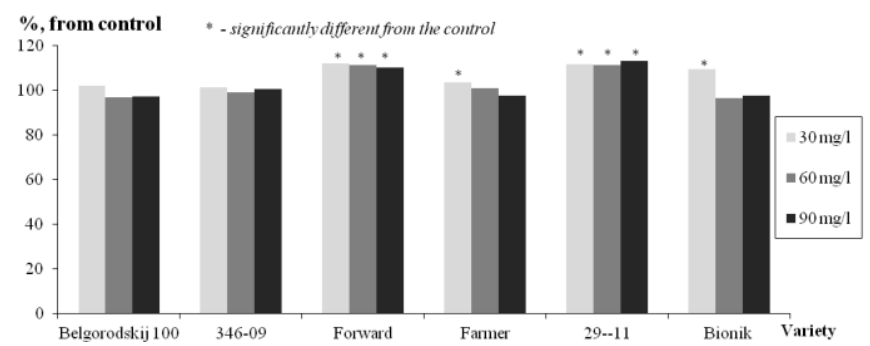

Fig. 1. Changes in the activity of superoxide dismutase in barley leaves under the action of manganese (II) ions.

For most of the studied varieties of barley, there were no significant changes in AOA under the action of an excess (60 and $90 \mathrm{mg} / \mathrm{l}$ ) of manganese (II) ions. For the Farmer and Bionik varieties, an increase in AOA was recorded under the influence of the lowest concentrations of manganese (II) ions studied in the experiment. In the case of the Forward and 29-11 varieties, an increase in AOA was recorded in the entire range of the studied concentrations of manganese.

According to the literature, there is a close relationship between the activity of SOD and the resistance of plants to adverse factors. At the same time, the activity of SOD varies in different directions [14]. On the one hand, excess Mn increases disorganization in chloroplast lamellae, which leads to disturbances of processes occurring in plant leaves [15]. For example, in Cucumis sativus plants, both the excess Mn and the optimal light intensity determine the increase in oxidative stress due to an increase in the Mn content in the tissues, which is accompanied by inhibition of plant growth [16]. On the other hand, the increased activity of SOD, which is a key antioxidant defense enzyme and contains manganese, limits cell damage $[14,15]$.

The content of chlorophyll $\mathrm{a}$ and $\mathrm{b}$ in the leaves of the studied barley varieties ranged from 7.8 to 22.6 and 3.9 to $12.9 \mathrm{mg} / \mathrm{g}$, respectively (Fig. 2). 

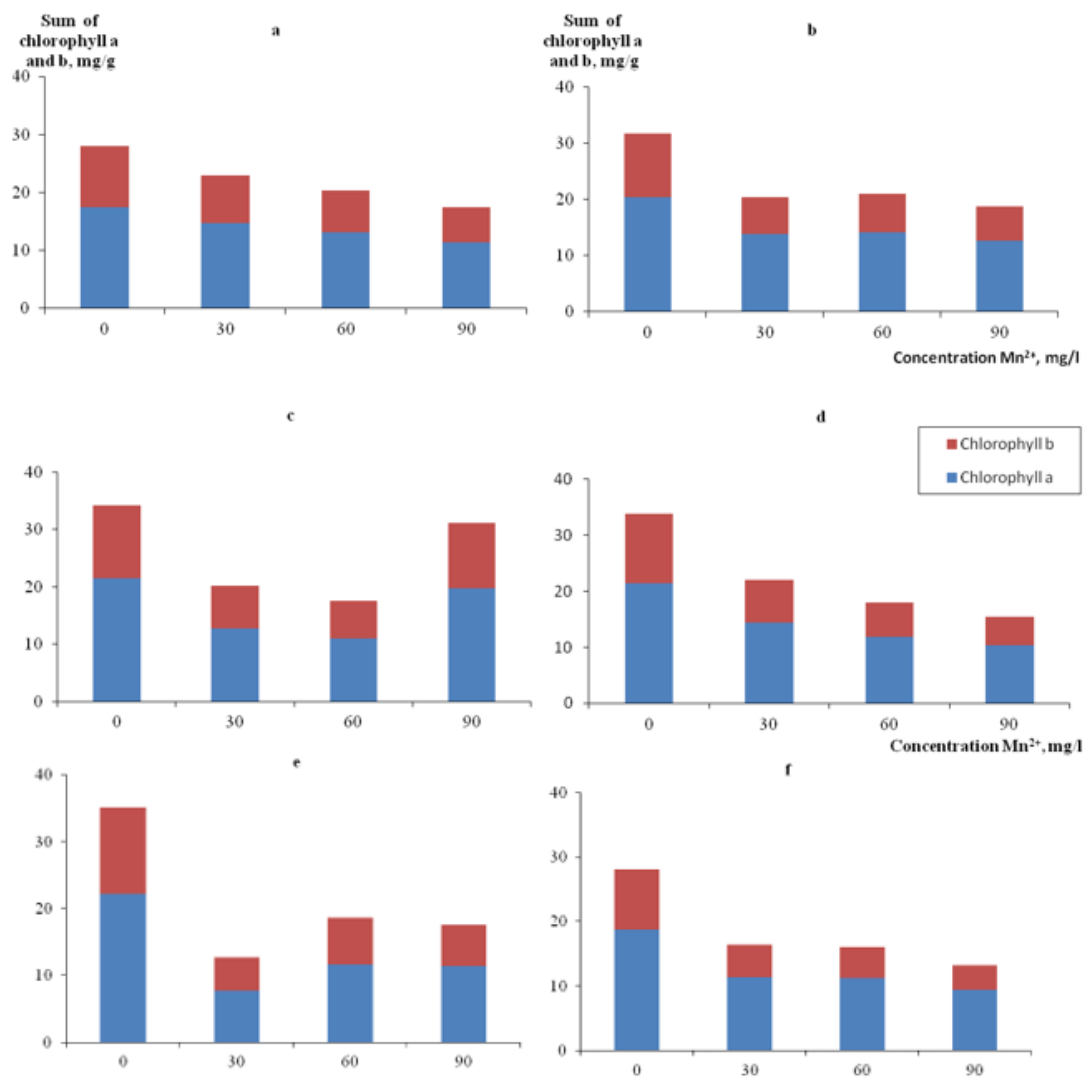

Fig. 2. The effect of manganese (II) ions on the chlorophyll content in the leaves of barley of the Belgorodskij 100 variety (a); 346-09 (b); Forward (c); Farmer (d); 29-11 (e); Bionik (f).

The introduction of manganese into the growing medium of the plant led to a decrease in the content of chlorophyll a in the barley leaves. In most of the studied varieties, with an increase in the concentration of manganese (II) ions in the growing medium, a decrease in the content of green pigments in the leaves was recorded. The exception was the variety Farmer and 29-11, the content of chlorophyll $a$ and $b$ in the leaves of which was less determined by the dose of manganese. Among the studied varieties, the lowest content of chlorophylls $\mathrm{a}$ and $\mathrm{b}$ in the leaves of the control variant was recorded in the variety Belgorodskij 100. In the Bionik variety, the content of chlorophyll $\mathrm{a}$ and $\mathrm{b}$ in the leaves did not significantly differ from the level of the standard variety.

The total amount of chlorophyll $\mathrm{a}$ and $\mathrm{b}$ in the barley leaves of the studied varieties varied from 12.7 to $35.1 \mathrm{mg} / \mathrm{g}$. The introduction of manganese into the growing medium led to a decrease in the total content of green pigments in the barley leaves. According to the literature, the decrease in the content of green pigments in plants in the presence of heavy metals can be caused by the suppression of its biosynthesis or activation of the processes of destruction of chlorophyll [17]. In the Forward variety, the content of green pigments significantly decreased, compared with the control, only under the action of $\mathrm{Mn}^{2+}$ at a dose of 30 and $60 \mathrm{mg} / \mathrm{l}$.

The content of carotenoids in the leaves of the studied barley varieties varied from 1.6 to $4.9 \mathrm{mg} / \mathrm{g}$. Among the studied varieties, the minimum values of the content of carotenoids 
in the leaves of the control variant were established in the variety Belgorodskij 100 (Table 1).

In the variants of the experiment, in comparison with the control, a decrease in the content of carotenoids in the leaves was noted. Due to the fact that, as noted above, the metal-resistant varieties, as a rule, the content of carotenoids decreases slightly, in our studies, the variety 29-11 was less stable for this indicator, and the most stable - the variety Belgorodskij 100.

Table 1. Effect of manganese (II) ions on the content of carotenoids in barley leaves of different varieties $(\mathrm{mg} / \mathrm{g}) /$ mass ratio of the sum of chlorophyll $\mathrm{a}$ and $\mathrm{b}$ to carotenoids

\begin{tabular}{|l|c|c|c|c|}
\hline \multirow{2}{*}{ Variety } & \multicolumn{4}{|c|}{ Concentration $\mathrm{Mn}^{2+}, \mathrm{mg} / \mathrm{l}$} \\
\cline { 2 - 5 } & 0 & 30 & 60 & 90 \\
\hline Belgorodskij & $3.1 \pm 0.1 /$ & $2.8 \pm 0.2 /$ & $2.8 \pm 0.1 /$ & $2.8 \pm 0.1 /$ \\
100 & $9.2 \pm 0.3$ & $8.2 \pm 0.4$ & $7.2 \pm 0.4$ & $6.2 \pm 0.4$ \\
\hline $346-09$ & $3.9 \pm 0.2 /$ & $3.2 \pm 0.2 /$ & $3.2 \pm 0.2 /$ & $2.8 \pm 0.2 /$ \\
& $8.3 \pm 0.3$ & $6.3 \pm 0.2$ & $6.5 \pm 0.1$ & $6.6 \pm 0.4$ \\
\hline Forward & $4.9 \pm 0.1 /$ & $3.4 \pm 0.1 /$ & $2.9 \pm 0.3 /$ & $4.6 \pm 0.2 /$ \\
& $6.9 \pm 0.3$ & $5.9 \pm 0.1$ & $5.9 \pm 0.1$ & $6.8 \pm 0.3$ \\
\hline Farmer & $3.9 \pm 0.1 /$ & $2.9 \pm 0.2 /$ & $2.8 \pm 0.1 /$ & $2.7 \pm 0.1 /$ \\
& $8.9 \pm 0.2$ & $7.6 \pm 0.3$ & $6.3 \pm 0.5$ & $5.8 \pm 0.1$ \\
\hline 29-11 & $4.1 \pm 0.1 /$ & $1.6 \pm 0.5 /$ & $2.3 \pm 0.1 /$ & $2.5 \pm 0.1 /$ \\
& $8.6 \pm 0.1$ & $8.4 \pm 1.3$ & $8.1 \pm 0.2$ & $7.0 \pm 0.3$ \\
\hline Bionik & $4.0 \pm 0.3 /$ & $2.9 \pm 0.2 /$ & $3.3 \pm 0.1 /$ & $2.8 \pm 0.1 /$ \\
& $7.0 \pm 0.3$ & $5.8 \pm 0.4$ & $4.9 \pm 0.1$ & $4.7 \pm 0.2$ \\
\hline
\end{tabular}

The weight ratio of the sum of chlorophylls $a$ and $b$ to the total content of carotenoids is an indicator of the greenness of plants. Lower values of this parameter are an indicator of aging, stress, and damage to the plant and photosynthetic apparatus, which is expressed in a faster breakdown of chlorophylls than carotenoids. The leaves become more yellowishgreen [13]. With an increase in the concentration of manganese, a decrease in the values of the ratio of the sum of chlorophylls to carotenoids parameter was noted. The exception was the variety Forward and 29-11. At the maximum concentration of manganese (II) ions in the nutrient solution in the Forward variety, no significant differences were found from the control, in the 29-11 variety, only at a dose of 60 and $90 \mathrm{mg} / \mathrm{l}$ of manganese (II) ions, a decrease in the values of the mass ratio $(a+b) /$ carotenoids was recorded.

It is known that the change in the values of the ratio of the concentration of chlorophylls $\mathrm{a}$ and $\mathrm{b}$ to the content of carotenoids is considered as an adaptive reaction of the LCC of photosynthetic pigments to changes in environmental conditions [18]. In this regard, a decrease in the values of this parameter in our experiments may indicate a negative effect of increased concentrations of manganese (II) ions on the development of barley plants.

The content of anthocyanins in the leaves of plants of the studied barley varieties increased when exposed to manganese (II) ions (Fig. 3).

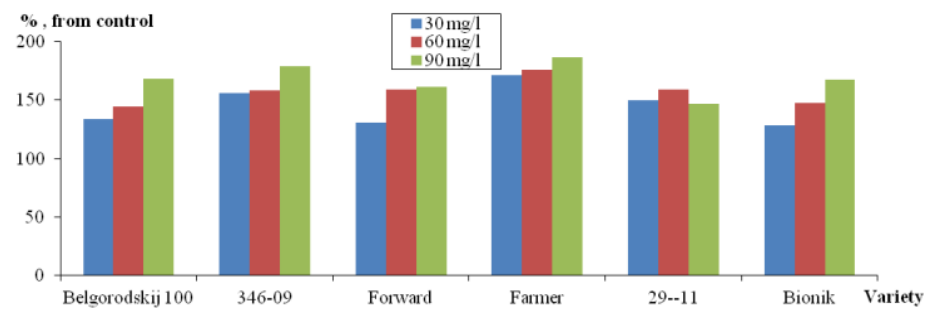

Fig. 3. Changes in the content of anthocyanins in barley leaves under the action of manganese (II) ions. 
The obtained data are consistent with the results of other researchers, according to which the number of anthocyanins in tissues under the influence of HM (for example, cadmium) increases in individual barley regenerants [19]. In most barley varieties studied, the maximum anthocyanin content in plant leaves was observed at an element concentration of $90 \mathrm{mg} / \mathrm{l}$. At the same time, the maximum change was recorded in the Farmer variety. The exception was the variety Forward and 29-11, for which there were no reliable differences in the content of anthocyanins at action 60 and $90 \mathrm{mg} / 1$.

\section{Conclusions}

1. It was found that the excess of $\mathrm{Mn}$ in the growing medium affects the antioxidant properties of seedlings of all the studied barley varieties and leads to the activation of plant protection mechanisms on the one hand and to the violation of physiological processes in them on the other hand.

2. According to the antioxidant activity of SOD in leaves, all the studied varieties are resistant to increased concentrations of manganese (II) ions, since it either has not changed (Belgorodskij 100 and 346-09 varieties) or has increased (Forward, Farmer, 29-11 varieties) in relation to control.

3. The most resistant to increased concentrations of manganese (II) ions is the variety Belgorodskij 100, since it did not show significant changes in the AOA SOD in the leaves, and the change in the content of carotenoids in them had the lowest value compared to other varieties.

4. The least resistant to increased concentrations of manganese (II) ions are the Farmer variety, since it has the highest change in the content of anthocyanins in the leaves compared to other varieties, and the 29-11 variety, since it has the highest change in the content of carotenoids compared to other varieties.

\section{References}

1. N. S. Kasimov, D. V. Vlasov, MSU Vestnik. Geography, 5(3), (2018)

2. A. E. Pobilat, E. I. Voloshin, Trace Elements in Medicine, 18(2), 43 (2017)

3. S. B. Schmidt, S. Husted, Plants, 8(10), 381 (2019)

4. Q. Shi, Z. Zhu, Environ. Exp. Bot., 63, 317 (2008)

5. M. Skórka, A. Sieprawska, E. Bednarska-Kozakiewicz, K. Gawrońska, A. Kornaś A. Telk, Agronomy, 10(4), 510 (2020)

6. S. Dong, H. Y. Yang, W. L. Wu, W. L. Li, L. Lyu, Brazilian Journal of Botany, 1 (2020)

7. H. R. Roosta, A. Estaji, F. Niknam, Photosynthetica, 56, 606 (2018)

8. G. N. Chupahina, P. V. Maslennikov, L. N. Skrypnik, N. YU. Chupahina, P. V. Feduraev, Antioxidant properties of cultivated plants of the Kaliningrad region, 145 (2016)

9. X. Chen, J. Wang, Y. Shi et al, Botanical Studies, 52, 41 (2011)

10. A. Wahid, A. Ghani, F. Javed, Agron. Sustian. Dev., 28, 273 (2008)

11. N. M. Kaznina, YU. V. Batova, A. F. Titov, G. F. Lajdinen, Transactions of the Karelian Research Centre of the Russian Academy of Sciences, 11, 17 (2016)

12. T. V. Sirota, Patent № 2144674, Application № 99103192 (1999) 
13. H. K. Lichtenthaler, C. Bushmann, Current Protocols in Food Analytical Chemistry, 4.3.1 (2001)

14. N. V. Zagoskina, L. V. Nazarenko, Vestnik Moscow city university. Natural Sciences, 2(22), 9 (2016)

15. F. C. Lidon, M. G. Teixeira, Plant Sci., 152, 7 (2000)

16. Q. Shi, Z. Zhu, M. Xu, Q. Qian, J. Yu, Environ. Exp. Bot., 58, 197 (2006)

17. J. Molas, Photosynthetica, 34(4), 513 (1997)

18. Yu. E. Aganina, S. N. Tarhanov, N. A. Prozherina, News of Samara Scientific Center of the Russian Academy of Sciences, 20(5), 118 (2018)

19. I. G. SHirokih, O. N. SHuplecova, E. V. Tovstik, S. Yu. Ogorodnikova, Ya. I. Nazarova, G. I. Berezin, Agricultural Science Euro-North-East, 65(4), 19 (2018) 